Research Article

\title{
Study of prevalence and pattern of dyslipidaemia in type 2 diabetes mellitus patients attending rural health training centre of medical college in Bhopal, Madhya Pradesh, India
}

\author{
Amod L. Borle*, Neeraj Chhari, Girjesh Gupta, Vishal Bathma
}

Department of Community Medicine, PCMS \& RC, Bhopal, MP, India

Received: 04 October 2015

Accepted: 07 November 2015

*Correspondence:

Dr. Amod L. Borle,

E-mail: dramodborle@rediffmail.com

Copyright: ( ) the author(s), publisher and licensee Medip Academy. This is an open-access article distributed under the terms of the Creative Commons Attribution Non-Commercial License, which permits unrestricted non-commercial use, distribution, and reproduction in any medium, provided the original work is properly cited.

\begin{abstract}
Background: Diabetes is endemic globally with increasing prevalence in both developing and developed countries. Persistent hyperglycaemia of diabetes is associated with micro as well as macro vascular complications like coronary heart disease, stroke, diabetic renal disease, diabetic retinopathy and neuropathy etc. Dyslipidemia contribute to considerable increased risk of atherosclerosis and consequent mortality in diabetic patients. It often precedes onset of diabetes particularly type 2 DM and may persist inspite of adequate control of blood sugar. The objective of the study was to study prevalence and pattern of dyslipidemia in type 2 diabetes mellitus patients attending Rural Health and Training Centre of medical college in Bhopal, Madhya Pradesh.

Methods: This was a cross sectional study carried out among 50 Type 2 diabetic mellitus patients attending OPD of Rural Health Training Centre (RHTC) of medical college in Bhopal Madhya Pradesh. Study population included known as well as newly diagnosed type 2 diabetic patients more than 30 years of age attending OPD at RHTC.

Results: According to ATP III guidelines dyslipidemia was observed in $43(86 \%)$ study subjects. Hypercholesterolemia was seen in $18(36 \%)$ study subjects. Increased LDL and triglycerides was observed in 33 $(66 \%)$ and $32(64 \%)$ study subjects respectively. Lower HDL cholesterol values were observed in 26 (52\%) study subjects. Out of 43 study subjects having dyslipidemia, $14(32.6 \%)$ study subjects were having isolated single parameter dyslipidemia, while $10(23.2 \%)$ had combined two parameter dyslipidemia and $19(44.2 \%)$ study subjects showed mixed dyslipidemia.

Conclusion: Results suggest high (86\%) prevalence of dyslipidemia among type 2 diabetes mellitus study subjects. Most common pattern observed was mixed type dyslipidemia. These lipid abnormalities might be the important in view of development of cardiovascular or cerebrovascular diseases. Hence type 2 diabetic patient should undergo the routine monitoring of blood sugar and lipid profile so that any abnormalities can be identified and preventive measures along with interventions can be initiated at the earliest.
\end{abstract}

Keywords: Type 2 Diabetes Mellitus, Dyslipidemia, Pattern, Lipid profile

\section{INTRODUCTION}

Diabetes mellitus (DM) has become major public health problem in India. It is a metabolic disorder caused by impaired insulin secretion, peripheral insulin resistance or both. It is characterised by raised blood glucose with diminished uptake and metabolism of cellular glucose as well as altered lipid and protein metabolism. ${ }^{1}$ Diabetes is not only increasing morbidity and mortality but also decreases the quality of life. Also disease and its complications are causing heavy economic burden for patients suffering from it. ${ }^{2,3}$ 
Diabetes is endemic globally with increasing prevalence in both developing and developed countries. According to International Diabetes Federation there were 41 million diabetic patients in India (2006) which are projected to raise to 70 million in 2025 . Out of these more than $90 \%$ are type 2 diabetic patients. ${ }^{4}$

Persistent hyperglycaemia of diabetes is associated with micro as well as macro vascular complications like coronary heart disease, stroke, diabetic renal disease, diabetic retinopathy and neuropathy etc. Altered lipid metabolism and altered lipid levels are major contributors to macrovascular complications.

"Dyslipidemia" is the term used widely to describe the abnormal lipid profile. Dyslipidemia contribute to considerable increased risk of atherosclerosis and consequent mortality in diabetic patients. It often precedes onset of diabetes particularly type $2 \mathrm{DM}$ and may persist inspite of adequate control of blood sugar. ${ }^{1}$ The typical diabetic dyslipidemia is characterised by elevations of triglycerides (TG), low density lipoproteins (LDL) and decreased high density lipoproteins values.

In type 2 diabetics insulin resistance causes unrestricted lipolysis leading to increased fatty acid flux in liver and ends in higher hepatic triglyceride synthesis. Also the activity of endothelial insulin dependent lipoprotein lipase is less resulting in decreased triglyceride clearance. Other processes involving apoprotein production and action of cholesteryl ester also get affected. ${ }^{1}$

Patients having diabetic dyslipidemia have lipid particles that are more atherogenic than in non-diabetic people. ${ }^{5}$ Because of this additive cardiovascular risk of hyperglycemia and hyperlipidemia, it is needed to detect and treat the lipid abnormalities at the earlier. In view of this present study was conducted with objective to study prevalence and pattern of dyslipidemia in type 2 diabetes mellitus patients attending Rural Health and Training Centre of medical college in Bhopal, Madhya Pradesh.

\section{METHODS}

This was a cross sectional study carried out among type 2 diabetic mellitus patients attending OPD of Rural Health Training Centre (RHTC) of medical college in Bhopal Madhya Pradesh. The study was conducted during period of one and half year between March 2013 and October 2014. Study population included known as well as newly diagnosed type 2 diabetic patients more than 30 years of age attending OPD at RHTC. Study was conducted among 50 study subjects using convenient sampling method.

\section{Inclusion Criteria}

a) Patient with $>30$ years of age

b) Known case of type $2 \mathrm{DM}$ c) Newly diagnosed case of type 2 diabetes diagnosed as per criteria of American diabetics association: ${ }^{2}$

1. Fasting plasma glucose level higher than 126 $\mathrm{mg} / \mathrm{dl}$ or

2. Plasma Glucose level exceeding $200 \mathrm{mg} / \mathrm{dl}$ at 2 hours in the $75 \mathrm{~g}$ oral glucose tolerance test or

3. Symptoms of Diabetes and Random Plasma Glucose $>200 \mathrm{mg} / \mathrm{dl}$ or

4. $\mathrm{HbA} 1 \mathrm{C}>6.5 \%$.

\section{Exclusion criteria}

Patients with following conditions were excluded:

- Acute metabolic complications - Diabetic ketoacidosis, hyperglycemic hyperosmolar syndrome

- Acute illnesses - Acute myocardial infarction, cerebrovascular disease, acute infections.

- Hypothyroidism

- Liver disorder

- Renal diseases

- Patients on beta blocker, diuretics, thiazides

\section{Data collection}

Ethical clearance was obtained from Institutional Ethics Committee. Study subjects were assured regarding the confidentiality. Before the personal interview objective of the study was explained to participants and informed consent was taken. Data was collected with the help of interview technique followed by clinical examination and necessary investigations. History taking included personal details, socio-demographic details, family history, presenting complaints, past history, and treatment history.

For the blood sample collection 12 hours of fasting was observed. Under all aseptic precautions, $5 \mathrm{ml}$ each fasting and post meal samples were obtained from each study subject with the help of disposable syringe and needle. Lipid profile was estimated by enzyme kit method. Fasting as well as post meal blood sugar (PMBS) level was quantitatively estimated using semi auto analyser.

For serum lipid reference level national cholesterol education programme (NCEP) adult treatment panel III (ATP III) guidelines were referred. ${ }^{6}$ Dyslipidaemia was defined as one or more from the following criteria: as diagnosed previously by physician, elevated LDL-C (> $100 \mathrm{mg} / \mathrm{dl})$, or TG (>150 mg/dl); a low HDL-C $(<40$ $\mathrm{mg} / \mathrm{dl}$ ); or a combination of these abnormalities and for patients who reported being prescribed for lipid lowering drugs. Dyslipidaemia was divided into two types: isolated dyslipidaemia (one of the lipid fractions is out of the target level) and combination dyslipidaemia (two lipid fractions are out of the target level). ${ }^{7}$ 


\section{Statistical Analysis}

Data was analyzed using Statistical Package for Social Sciences (SPSS) version 20 and Microsoft Excel. Descriptive statistics used was mean, standard deviation and percentage. For inferential statistics Unpaired ' $t$ ' test was used. P-value of $<0.05$ was taken as statistically significant difference.

\section{RESULTS}

The present study was carried out among 50 study subjects to find out the prevalence and pattern of dyslipidemia in type 2 diabetes mellitus patients. Out of 50 study subjects 29 were males and 21 were females. Mean age for males was $41.3 \pm 3.3$ years and for females was $40.5 \pm 3.2$ years. There was no statistically significant difference observed between them. Mean and standard deviation of various lipid profile parameters was shown in table 1. Males were having slightly higher values of lipid profile parameters but this difference was statistically insignificant.
Table 1: Distribution of clinical parameters in study subject.

\begin{tabular}{|c|c|c|c|c|c|}
\hline \multirow{2}{*}{ Variable } & \multicolumn{2}{|l|}{ Males } & \multicolumn{2}{|c|}{ Females } & \multirow{2}{*}{$\begin{array}{l}\text { p } \\
\text { value }\end{array}$} \\
\hline & Mean & SD & Mean & SD & \\
\hline Age (years) & 41.3 & 3.3 & 40.5 & 3.2 & 0.39 \\
\hline $\begin{array}{l}\text { Fasting blood } \\
\text { sugar }(\mathrm{mg} / \mathrm{dl})\end{array}$ & 152.2 & 22.5 & 146.4 & 21.6 & 0.36 \\
\hline $\begin{array}{l}\text { Post prandial } \\
\text { blood sugar } \\
(\mathrm{mg} / \mathrm{dl})\end{array}$ & 243.7 & 27.5 & 252.3 & 25.4 & 0.27 \\
\hline $\begin{array}{l}\text { Triglycerides } \\
(\mathrm{mg} / \mathrm{dl})\end{array}$ & 200.6 & 90.2 & 192.7 & 71.8 & 0.74 \\
\hline $\begin{array}{l}\text { Total } \\
\text { cholesterol } \\
(\mathrm{mg} / \mathrm{dl})\end{array}$ & 194.9 & 25.8 & 182.5 & 30.7 & 0.12 \\
\hline HDL-C (mg/dl) & 38.9 & 7.9 & 39.5 & 8.4 & 0.79 \\
\hline LDL-C (mg/dl) & 116.3 & 24.6 & 111.2 & 27.3 & 0.49 \\
\hline
\end{tabular}

Table 2: Distribution of lipid profile parameters according to NCEP ATP III classification.

\begin{tabular}{|c|c|c|c|c|c|c|c|}
\hline \multirow{2}{*}{ Variables } & & \multicolumn{2}{|c|}{ Males $(\mathbf{n}=29)$} & \multicolumn{2}{|c|}{ Females $(n=21)$} & \multicolumn{2}{|c|}{ Total $(\mathrm{n}=\mathbf{5 0})$} \\
\hline & & $\mathbf{N}$ & $\%$ & $\mathbf{N}$ & $\%$ & $\mathbf{N}$ & $\%$ \\
\hline \multicolumn{8}{|c|}{ LDL-Cholesterol (mg/dl) } \\
\hline$<100$ & Optimal & 9 & 31.0 & 8 & 38.1 & 17 & 34 \\
\hline $100-129$ & Near optimal/ above optimal & 12 & 41.4 & 7 & 33.3 & 19 & 38 \\
\hline $130-159$ & Borderline high & 6 & 20.7 & 5 & 23.8 & 11 & 22 \\
\hline $160-189$ & High & 2 & 6.9 & 1 & 4.8 & 3 & 6 \\
\hline$>190$ & Very high & 0 & 0.0 & 0 & 0.0 & 0 & 0 \\
\hline \multicolumn{8}{|c|}{ Total Cholesterol (mg/dl) } \\
\hline$<200$ & Desirable & 17 & 58.6 & 15 & 71.4 & 32 & 64 \\
\hline $200-239$ & Borderline high & 9 & 31.0 & 4 & 19.0 & 13 & 26 \\
\hline$>240$ & High & 3 & 10.3 & 2 & 9.5 & 5 & 10 \\
\hline \multicolumn{8}{|c|}{ HDL Cholesterol (mg/dl) } \\
\hline$<40$ & Low & 15 & 51.7 & 11 & 52.4 & 26 & 52 \\
\hline $40-60$ & Normal & 14 & 48.3 & 10 & 47.6 & 24 & 48 \\
\hline$>60$ & High & 0 & 0.0 & 0 & 0.0 & 0 & 0 \\
\hline \multicolumn{8}{|c|}{ Triglycerides (mg/dl) } \\
\hline$<150$ & Normal & 12 & 41.4 & 6 & 28.6 & 18 & 36 \\
\hline $150-199$ & Borderline high & 10 & 34.5 & 11 & 52.4 & 21 & 42 \\
\hline $200-499$ & High & 6 & 20.7 & 4 & 19.0 & 10 & 20 \\
\hline$>500$ & Very high & 1 & 3.4 & 0 & 0.0 & 1 & 2 \\
\hline
\end{tabular}

Mean fasting blood glucose in males was $152.2 \pm 22.5$ $\mathrm{mg} / \mathrm{dl}$ and that in females was $146.4 \pm 21.6 \mathrm{mg} / \mathrm{dl}$. While post prandial blood glucose values for males and females were $243.7 \pm 27.5$ and $252.3 \pm 25.4 \mathrm{mg} / \mathrm{dl}$ respectively. There was no significant difference between blood glucose levels of males and females. Distribution of lipid profile parameters according to sex was graphically represented using box and whiskers plot in Figure 1.
According to ATP III guidelines dyslipidemia was observed in $43(86 \%)$ study subjects. Lipid profile parameters distribution as per classification given by NCEP ATP III guideline was shown in table 2. Hypercholesterolemia was seen in 18 (36\%) study subjects. Increased LDL and triglycerides was observed in $33(66 \%)$ and $32(64 \%)$ study subjects respectively. Lower HDL cholesterol values were observed in 26 $(52 \%)$ study subjects. 


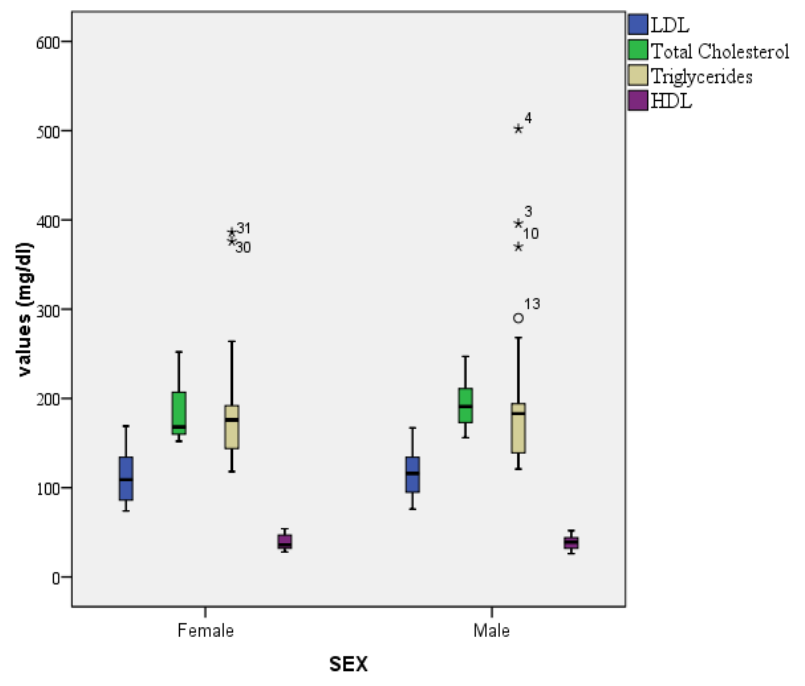

Figure 1: Box and whiskers plot showing distribution of lipid profile parameters according to sex.

Table 3: Pattern of dyslipidaemia among study subjects.

\begin{tabular}{|c|c|c|c|c|c|c|}
\hline \multirow{2}{*}{$\begin{array}{l}\text { Pattern of } \\
\text { dyslipidaemia }\end{array}$} & \multicolumn{2}{|c|}{$\begin{array}{l}\text { Males } \\
(n=29)\end{array}$} & \multicolumn{2}{|c|}{$\begin{array}{l}\text { Females } \\
(\mathrm{n}=\mathbf{2 1})\end{array}$} & \multicolumn{2}{|c|}{$\begin{array}{l}\text { Total } \\
(\mathrm{n}=50)\end{array}$} \\
\hline & $\mathbf{N}$ & $\%$ & $\mathbf{N}$ & $\%$ & $\mathbf{N}$ & $\%$ \\
\hline $\begin{array}{l}\text { 1) Mixed } \\
\text { dyslipidaemia } \\
\text { (LDL } \geq 100, T G \geq 150 \\
\text { \& } \mathrm{HDL}<40 \text { ) }\end{array}$ & 11 & 37.9 & 08 & 38.1 & 19 & 38 \\
\hline $\begin{array}{l}\text { 2) Combined two } \\
\text { parameter } \\
\text { dyslipidaemia. }\end{array}$ & 05 & 17.2 & 05 & 23.8 & 10 & 20 \\
\hline $\begin{array}{l}\text { a. }(\mathrm{LDL} \geq 100, \mathrm{TG} \geq 1 \\
50 \& \mathrm{HDL}>40)\end{array}$ & 02 & 06.9 & 02 & 09.5 & 04 & 08 \\
\hline $\begin{array}{l}\text { b. }(\mathrm{LDL}<100, \mathrm{TG} \geq 1 \\
50 \& \mathrm{HDL}<40)\end{array}$ & 01 & 03.4 & 03 & 14.3 & 04 & 08 \\
\hline $\begin{array}{l}\text { c. } \mathrm{LDL} \geq 100, \mathrm{TG}<15 \\
0 \& \mathrm{HDL}<40)\end{array}$ & 02 & 06.9 & 00 & 00.0 & 02 & 04 \\
\hline $\begin{array}{l}\text { 3) Isolated single } \\
\text { parameter } \\
\text { dyslipidaemia }\end{array}$ & 09 & 31.0 & 05 & 23.8 & 14 & 28 \\
\hline $\begin{array}{l}\text { a.LDL } \geq 100 \\
, \mathrm{TG}<150, \mathrm{HDL}>40)\end{array}$ & 05 & 17.2 & 03 & 14.3 & 08 & 16 \\
\hline $\begin{array}{l}\text { b. } \mathrm{LDL}<100, \mathrm{TG} \geq 15 \\
0 \& \mathrm{HDL}>40 \text { ) }\end{array}$ & 03 & 10.3 & 02 & 09.5 & 05 & 10 \\
\hline $\begin{array}{l}\text { c. } \mathrm{LDL}<100, \mathrm{TG}<15 \\
0 \& \mathrm{HDL}<40)\end{array}$ & 01 & 03.4 & 00 & 00.0 & 01 & 02 \\
\hline
\end{tabular}

Single as well as combined lipid parameter abnormalities were observed in study subjects. Out of 43 study subjects having dyslipidemia, $14(32.6 \%)$ study subjects were having isolated single parameter dyslipidemia, while 10 (23.2\%) had combined two parameter dyslipidemia and
$19(44.2 \%)$ study subjects showed mixed dyslipidemia (Table 3).

\section{DISCUSSION}

Type 2 diabetes mellitus accounts for more than $90 \%$ of cases of diabetes mellitus, leading to major public health burden in community. Dyslipidemia is one of the important metabolic abnormalities related with diabetes mellitus. Present study was carried to assess the prevalence and pattern of dyslipidemia in type 2 diabetes mellitus patients. In the present study it was observed that type 2 diabetic patients had poor glycemic control which was reflected by higher values of fasting and post prandial blood sugar.

In this study males shows slightly higher levels of lipid profile parameters as compared to females but this difference was statistically insignificant. These findings were similar to those observed by Kondveeti et $\mathrm{al}^{8}$ in Tamilnadu, Rajput et $\mathrm{al}^{9}$ in Bhopal and Agarwal Y et al ${ }^{10}$ in a study carried out in Haryana.

In our study prevalence of dyslipidemia was found to be $86 \%$ which was similar to that studied by Agarwal Y et $\mathrm{al}^{10}$, Pandya $\mathrm{H}$ et al ${ }^{11}$, Jayrama $\mathrm{N}$ et $\mathrm{al}^{12}$ and Dixit et al. ${ }^{13}$ The observed prevalence was higher as compared to that observed by Rajput et $\mathrm{al}^{9}$, and Kondveeti et al. ${ }^{8}$ This increased prevalence might be due to poor glycemic control in study subjects.

Present study showed hypercholesterolemia in $36 \%$ study subjects while $66 \%$ study subjects had increased LDL and $64 \%$ had increased triglycerides. Low HDL was observed among 52\% study subjects. Along with isolated dyslipidemia combined lipid fraction abnormalities were also seen. Most common pattern of dyslipidemia was of mixed type where LDL and triglycerides were increased and HDL was decreased. Among study subjects with dyslipidemia $44.2 \%$ had mixed dyslipidemia , 32.6\% had isolated single parameter dyslipidemia and $23.2 \%$ had combined two parameter dyslipidemia. Similar findings were observed by Cook et al, ${ }^{14}$ Rakesh et al $^{15}$ and Pandya H et al. ${ }^{11}$

Abnormal lipid profile observed in type 2 DM was related to insulin resistance which leads to increased release of free fatty acids from fatty tissue and impaired insulin dependent muscle uptake of free fatty acids. ${ }^{16}$

Chronic hyperglycemia causes glycation of apolipoproteins and interferes with the normal pathways of lipoprotein metabolism. ${ }^{17}$ Lipoprotein lipase an insulin dependent enzyme, together with insulin resistance leads to increase in $\mathrm{TG}$ levels, which causes increase in triglyceride levels. Reduction in HDL-C levels in DM may be due to elevated hepatic lipase activity that catalyses HDL-C. ${ }^{18}$ 
Patients having dyslipidemia were already at enhanced risk of cardiovascular and cerebrovascular events and certainly require therapeutic interventions.

\section{CONCLUSION}

Results suggest high (86\%) prevalence of dyslipidemia among type 2 diabetes mellitus study subjects. Most common pattern observed was mixed type dyslipidemia. These lipid abnormalities might be the important in view of development of cardiovascular or cerebrovascular diseases. Hence type 2 diabetic patient should undergo the routine monitoring of blood sugar and lipid profile so that any abnormalities can be identified and preventive measures along with interventions can be initiated at the earliest.

\section{Limitations}

As the study was carried out among patients attending OPD of RHTC, results can't be generalized to general population. Also factors like pattern of glycemic control, duration of disease were not considered so further studies are required in this issue.

\section{Funding: No funding sources}

Conflict of interest: None declared

Ethical approval: The study was approved by the Institutional Ethics Committee

\section{REFERENCES}

1. Sheshiah V, Balaji V. A handbook on Diabetes Mellitus. 6th ed. New Delhi: all india publishers \& distributers. 2013:29-54.

2. American Diabetes Association. Diagnosis and Classification of Diabetes Mellitus, Diabetes Care. 2011,34,62-9.

3. Ramachandran A, Snehalatha C. Current scenario of diabetes in India, J. Diabetes. 2009;1(1):18-8.

4. Sicree R, Shaw J, Zimmet P. Diabetes and impaired glucose tolerance. In: Gan D, Diabetes Atlas. International Diabetes Federation, 3rd ed. Belgium: International Diabetes Federation. 2006;15-103.

5. Goldberg IJ. Clinical review 124: Diabetic Dyslipidemia: Causes and Consequences. J Clin Endocrinol Metabol. 2001;86:965-71.

6. Antonopoulos S. Third report of the National Cholesterol Education Program (NCEP) expert panel on detection, evaluation, and treatment of high blood cholesterol in adults (Adult Treatment Panel III) final report. Circulation. 2002;106:3143-421.

7. Erem C, Hacihasanoglu A, Deger O, Kocak M, Topbas M. Prevalence of dyslipidemia and associated risk factors among Turkish adults: Trabzon lipid study. Endocrine. 2008;34(1):36-51.
8. Kondaveeti SB, Shekar AI, Kumar A, Palwan H, Raja G. Evaluation of glycated albumin and dyslipidemia in type-2 diabetes mellitus. International journal of Bioassays. 2012;01(11):112 -15 .

9. Rajput DP, Shah JY, Singh P, Jain S. Evaluation of dyslipidemia in type 2 diabetes mellitus. Asian Journal of Medical sciences. 2015;6(6):16-20.

10. Agrawal Y, Goyal V, Chugh K, Shanker V, Singh A. Types of Dyslipidemia in Type 2 Diabetic Patients of Haryana Region. Sch. J. App. Med. Sci. 2014;2(4D):1385-92.

11. Pandya H, Lakhani JD, Dadhania J, Trivedi A. The Prevalence and Pattern of Dyslipidemia among Type 2 Diabetic Patients at Rural Based Hospital in Gujarat, India. Indian Journal of Clinical Practice 2012;22(12):36-44.

12. Jayarama N, Reddy M, Lakshmaiah V. Prevalence and pattern of dyslipidemia in type 2 diabetes mellitus patients in a rural tertiary care centre, southern India. Global Journal of Medicine and Public Health. 2012;1(3):24-8.

13. Dixit AK, Dey R, Suresh A, Chaudhuri S, Panda AK, Mitra A. The prevalence of dyslipidemia in patients with diabetes mellitus of ayurveda Hospital. Journal of Diabetes \& Metabolic Disorders. 2014;13:58.

14. Cook CB, Erdman DM, Ryan GJ, Greenlund KJ, Giles WH, Gallina DL et al. The pattern of dyslipidemia among urban African-Americans with type 2 diabetes. Diabetes Care, 2000; 23(3): 319324.

15. Parikh RM, Joshi SR, Menon PS, Shash NS. Prevalence and Pattern of Diabetic Dyslipidemia in Indian type 2 Diabetic patients. Diabetes and Metabolic Syndrome; Clinical Research and Review. 2010;4(1):10-2.

16. Boden G; Role of fatty acids in the pathogenesis of insulin resistance and NIDDM. Diabetes, 1997;46(1): 3-10.

17. Carmena R. High risk of lipoprotein dysfunction in type 2 diabetes mellitus. Rev Esp Cardiol Supl. 2008;8(supl C):18C-24C.

18. Harno KE, Nikkila EA, Kuusi T. Plasma HDL cholesterol and post-hepatic plasma hepatic endothelial lipase activity. Relationship to Obesity and NIDDM. Diabetologia. 2008;19:281-5.

Cite this article as: Borle A, Chhari N, Gupta G, Bathma V. Study of prevalence and pattern of Dyslipidaemia in Type 2 Diabetes Mellitus patients attending Rural Health Training Centre of medical college in Bhopal, Madhya Pradesh, India . Int J Community Med Public Health 2016;3:140-4. 